\title{
UM PROJETO DE TRADUÇÃO EXPRESSIVA: ÉDIPO E FENÍCIAS, DE SÊNECA
}

\author{
Cíntia Martins Sanches` \\ Universidade Estadual Paulista "Júlio de Mesquita Filho"
}

\begin{abstract}
This article deals with procedures for expressive translation of Seneca's tragedies, Oedipus and Phoenissae. The research is part of a project of study on expressiveness in such tragedies, defining the stylistic idiom used by the author in both plays, so that those expressiveness' marks from source texts can be valued and transferred into target texts. Thus, besides the translation project itself, the expressive effects on a small part of Phoenissae (654-659) are presented and, finally, the verses are translated into Brazilian Portuguese.
\end{abstract}

KEYWORDS: expressive translation; tragedy; Seneca; Oedipus; Phoenissae.

presente estudo faz parte de uma pesquisa sobre a expressividade das tragédias senequianas Édipo e Fenícias, a fim de delimitar o idioma estilístico do autor latino no tratamento da saga dos Labdácidas, bem como propor uma tradução expressiva para esses dois dramas. Assim, este artigo: 1) discorre sobre o projeto tradutório que norteia o trabalho;2) exemplifica o que será feito no projeto com as tragédias citadas, a partir de exemplos retirados dos dois textos, pontuando os procedimentos poéticos utilizados para, depois, propor a transposição expressiva dos versos do latim para o português.

A tradução de um texto de uma língua para outra busca ultrapassar muitos obstáculos linguísticos, culturais e temporais. Quando os textos

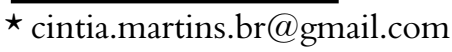


foram escritos há mais de dois mil anos, em uma língua sobre cuja prosódia, no período clássico, não se tem absoluta certeza, o que inevitavelmente afeta a depreensão total dos jogos de palavras e de sons, os obstáculos se multiplicam. Quando se trata de uma obra literária, em que há necessidade de verter valores artísticos por meio da língua de chegada, há um universo inteiro de dificuldades para serem enfrentadas. Dessa forma, faz-se fundamental para este estudo a definição de tradução de Brodsky: "A tradução é a procura de um equivalente, e não de um substituto. Requer pelo menos uma afinidade estilística, quando não psicológica". ${ }^{1}$

Procurar um equivalente significa, na medida do possível, verter sentido, estilo, intenção e tom, aliados ao contexto específico de cada verso. A mesma palavra de uma determinada língua não tem um substituto em outra língua. As palavras, os sentidos e os usos não são fixos: cada vocábulo tem diferentes significados, diferentes usos, em diferentes contextos. Por isso, Brodsky afirma ${ }^{2}$ que não é um substituto o que deve intentar uma tradução, mas um equivalente, ou seja, uma forma de dizer o que o autor do texto de partida quis dizer com aquele texto, procurando ao máximo se assemelhar à forma como ele quis dizer tal coisa. É preciso levar em consideração a sonoridade, o ritmo, a métrica, a unidade dos versos, os jogos de palavras, as figuras de linguagem, o estilo (como marca pessoal do autor). A tradução deve transpor a atmosfera, a intenção, a reflexão que o texto permite ou provoca, segundo a interpretação de seu tradutor.

As tragédias Édipo e Fenícias — poemas dramáticos que são encerram um uso abundante e sofisticado de recursos expressivos, comumente classificados como figuras de linguagem, bem como por astúcias expressivas presentes nos planos fônico, lexical, morfossintático e métrico. A proposta é investigar como se orquestram expressão e conteúdo no enunciado poético, oferecendo uma tradução expressiva ou, nos termos de Brodsky, procurando um equivalente desses recursos em português.

\section{O conceito de idioma estilístico}

Brodsky, em "O filho da civilização", trata de traduções de textos do poeta Ossip Mandelstam para o inglês que ele julga serem de má qualidade, a partir do princípio de que "o mínimo que se pode esperar de seus tradutores [de Mandelstam] é pelo menos uma aparência de paridade

\footnotetext{
${ }^{1}$ Cf. Brodsky, 1994, p. 84.

${ }^{2}$ Cf. Brodsky, 1994, p. 84.
} 
[semblance of parity]" ${ }^{3} \mathrm{O}$ autor afirma que essa paridade pode ser conquistada por meio de uma afinidade estilística:

[...] o idioma estilístico [stylistic idiom] que poderia ser usado para traduzir Mandelstam é o do Yeats dos últimos anos (com quem também tem muito em comum do ponto de vista temático). [...] Mas além da perícia técnica e de uma afinidade psicológica, a coisa mais crucial que um tradutor de Mandelstam precisa possuir ou então desenvolver é um sentimento análogo [like-minded sentiment] ao seu pela civilização. ${ }^{4}$

Sobre o conceito de idioma estilístico, Vieira observa ${ }^{5}$ que "embora [...] não seja claramente explicitado, Brodsky parece ter em mente tanto questões temáticas (o que se depreende da alegada afinidade temática entre Mandelstam e Yeats), como também prosódicas”. Vieira acrescenta que:

O conceito de "idioma estilístico" é bastante inquietante e faz pensar nas analogias possíveis entre poetas, entre versos, entre poemas. De fato, na medida em que a tradução expressará uma leitura possível de um texto em determinado ambiente histórico e idiossincrático, a elaboração de um idioma estilístico estará condicionada a um ato interpretativo. ${ }^{6}$

Dessa forma, o raciocínio em torno desse conceito se completa com a noção de tradução como interpretação, presente nos seguintes dizeres de Barbosa:

Tradução agora não mais apenas como busca do Sentido [...] mas como produção de sentidos. Isto significa, sobretudo, imantar, para o campo magnético da tradução, um elemento fundamental: a interpretação. Na verdade, sob o ângulo da produção de sentidos, a tradução importa na possibilidade de ser caracterizada como veículo de interpretações. Traduzir já não significa buscar o Sentido, mas apontar para a própria feição polissêmica das linguagens. Tradutor: intérprete. $^{7}$

${ }^{3}$ Cf. Brodsky, 1994, p. 84.

${ }^{4}$ Cf. Brodsky, 1994, p. 84-85.

${ }^{5}$ Cf. Vieira, 2007, p. 103.

${ }^{6}$ Cf. Vieira, 2007, p. 103.

${ }^{7}$ Cf. Barbosa, 1986, p. 156. 
Estilo pode ser definido como a marca pessoal de determinado autor, ou, como afirma Chociay, como a "realização particular de um padrão", devendo considerar-se "o estilo como fator duplamente diferencial; o estilo como diferencial constante do individual em relação ao grupal, ou do grupal em relação ao subgrupal; o estilo como diferença humana". Assim, a noção de idioma estilístico contemplaria uma forma de transpor em outra língua não apenas as características de estilo de determinado autor, mas a expressividade de seu texto como um todo, seu tom, sua atmosfera. É preciso estudar o padrão utilizado pelo autor para que a transposição expressiva possa se realizar.

O projeto tradutório que está em questão aqui leva em consideração o que Brodsky afirma sobre os tradutores: "A voz com a qual e a partir da qual cada um trabalha tende a ser única. No entanto, o timbre, o registro e o ritmo que se refletem no metro dos versos são abordáveis". ${ }^{10}$ Assim, a tradução proposta das duas tragédias senequianas que retratam o mito de Édipo procura esse tipo de tratamento aos textos de partida, o que pressupõe uma cuidadosa investigação dos procedimentos poéticos utilizados verso a verso. Completa Brodsky: "O tratamento descuidado de qualquer um desses aspectos [metros, rimas, ritmo, timbre, registro] é no mínimo um sacrilégio, e na pior das hipóteses uma mutilação ou um assassinato". ${ }^{11}$

\section{Que metro usar}

O texto de Fenícias consta de 664 trímetros iâmbicos, metro tradicionalmente empregado nos diálogos dramáticos, e que é também bastante recorrente entre os 1061 versos que compõem Édipo. Lohner disserta sobre o uso desse metro por Sêneca:

De modo geral, a técnica de metrificação empregada por Sêneca obedece às normas estabelecidas pelos escritores do classicismo. Nos diálogos é utilizado o trímetro iâmbico adaptado pelos tragediógrafos da época de Augusto. Dessa adaptação resultam alguns procedimentos diferentes daqueles adotados pelos antigos autores gregos, destacando-se 1) a admissão do proceleusmático no primeiro

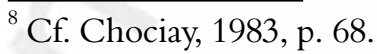

${ }^{9}$ Cf. Chociay, 1983, p. 74.

${ }^{10}$ Cf. Brodsky, 1994, p. 85.

${ }^{11}$ Cf. Brodsky, 1994, p. 85.
} 
pé; 2) o uso do pé puro na primeira posição; 3) a admissão do anapesto em todos os pés ímpares; 4) o uso do quinto pé sempre condensado; 5) a incidência da cesura pentemímera sobre um pé puro. ${ }^{12}$

Dado o investimento expressivo adotado pelo tragediógrafo romano nas suas peças, em especial no trímetro iâmbico, há de se refletir sobre a escolha métrica em português para a tradução desse verso. As opções adotadas para as peças de Sêneca variaram ao longo do tempo. No século XVIII, Cândido Lusitano traduziu o Édipo em decassílabos. ${ }^{13}$ Filinto Elísio, no final do século XVIII, ${ }^{14}$ verteu trechos da Medeia transpondo os trímetros iâmbicos para decassílabos. José Feliciano de Castilho, no século XIX, traduziu os 142 versos finais (v. 970-1112) de Thyestes ${ }^{15}$ utilizando, igualmente, os decassílabos para traduzir os trímetros iâmbicos, escolha que também se encontra na tradução da Fedra senequiana realizada por Sebastião Francisco Mendo Trigozo, que foi intitulada Hippolyto (1813). Mais recentemente, Joaquim Brasil Fontes (2007) traduziu a mesma obra, escolhendo predominantemente os dodecassílabos para verter esse metro latino. Lohner (2009), por fim, traduziu o drama Agamêmnon, exclusivamente pelo dodecassílabo em todas as ocorrências desse metro do diálogo. Quando não se tratava de trímetro iâmbico, todos esses tradutores serviram-se de outros tipos de metros.

Haroldo de Campos ${ }^{16}$ comenta algumas traduções poéticas de teatro grego no Brasil: João Cardoso de Meneses e Sousa, o Barão de Paranapiacaba, traduziu, de Ésquilo, o Prometeu Acorrentado (1902) em versos heptassílabos; Ramiz Galvão, o Barão de Ramiz, traduziu esse mesmo drama, utilizando, por sua vez, decassílabos, tradução essa que recebeu o nome de Prometeu Encadeado (1909). Além dessas, há, por exemplo, a tradução de Antígone, de Sófocles, por Guilherme de Almeida (editada em 1997 e publicada pela primeira vez em 1952), em hendecassílabos nas partes dialogadas e em versos polimétricos para os cantos corais. Também podem ser citados exemplos de traduções de Trajano Vieira, como Prometeu Prisioneiro e Agamêmnon, de Ésquilo, e Medeia, de Eurípides, nas quais é utilizado o decassílabo para verter as partes dialogadas, bem como versos polimétricos para os coros.

\footnotetext{
${ }^{12}$ Cf. Lohner, 2009, p. 145.

${ }^{13}$ Sêneca, 1769 (manuscrito da Biblioteca Pública de Évora).

${ }^{14}$ Cf. Filinto Elísio, 1998-2004 (obra reeditada recentemente).

${ }^{15}$ Ovídio, 1862, p. 161-166.

${ }^{16}$ Cf. Campos, 1997, p. 231-253.
} 
É possível, dessa forma, falar em uma tradição de metro para as traduções de tragédias em língua portuguesa. De acordo com essa tradição, os decassílabos ou os dodecassílabos poderiam ser escolhidos para a tradução aqui proposta. A escolha dos dodecassílabos se justificaria pela aproximação no número de sílabas existente entre esse metro e o trímetro iâmbico latino, o que permite que a unidade de cada verso seja mantida na maioria das vezes. Assim, cada verso latino seria traduzido por um único verso em português, e a tradução ficaria com o mesmo número de versos do texto de partida. É o que Lohner realiza em sua versão de Agamêmnon, como pode ser visto já nos primeiros versos do drama:

\section{Opaca linquens Ditis inferni loca}

adsum, profundo Tartari emissus specu. ${ }^{17}$

Apesar disso, e considerando as vantagens que a tradição de tradução decassilábica oferece para se verter poeticamente para o português, este projeto propõe que seja escolhido o verso de dez sílabas. A seleção do metro por um critério de equivalência apenas silábica pode parecer um tanto arbitrária, já que a equivalência que se visa a obter é a expressiva: o verso de dez sílabas proporciona tom solene, adequado a uma tragédia. O uso do decassílabo pode ser justificado, ainda, por uma tradição de equivalência que vem desde Antônio Ferreira, ${ }^{18}$ passando pela maioria dos autores e tradutores anteriormente citados. Dezotti discute o estabelecimento de relações entre os metros latinos e os portugueses durante a história da "correspondência" dos gêneros clássicos em contexto neolatino:

A partir do séc. XVI principalmente, os poetas da literatura portuguesa passaram a cultivar, em nosso idioma, os vários gêneros poéticos característicos das literaturas grega e latina, como a epopeia, a ode, a écloga, o epigrama, a epístola, etc. Para cada um desses gêneros, eles foram elaborando uma ou mais estruturas rítmicas, que certamente, eram tidas como correspondentes das estruturas empregadas pelos gregos e romanos. É claro que essa correspondência foi realizada de um modo puramente arbitrário e convencional. Mas o que importa

\footnotetext{
${ }^{17}$ Sêneca, 2009, p. 20-21: "Deixando a estância escura do deus infernal,/ eis-me, da funda gruta do Tártaro enviado".

${ }^{18}$ Em sua tragédia $A$ Castro (1587), escrita em decassílabos. Além dessa há outras tragédias metrificadas produzidas em língua portuguesa, entre as quais vale destacar Viriato (1757) e Ósmia (1773), de Manuel de Figueiredo, ambas predominantemente em decassílabos.
} 
salientar é que ela permitiu que se desenvolvesse nos leitores de língua portuguesa o hábito de associarem formas rítmicas próprias do nosso sistema poético a gêneros provenientes da antiguidade clássica. ${ }^{19}$

Assim, o decassílabo está intrinsecamente ligado ao gênero trágico, se se levarem em conta o histórico de correspondências em português nesse metro e a consequente equivalência estabelecida. Outrossim, a escolha do metro pode "projetar questões de estilo no texto de chegada" ${ }^{20}$ Nessa perspectiva, acredita-se que o decassílabo (sáfico ou heroico) está mais próximo daquilo que este trabalho pretende definir como idioma estilístico de Sêneca. Se o metro estabelece um ritmo ao texto e, se "cada ritmo é uma atitude, um sentido e uma imagem do mundo, distinta e particular", ${ }^{21}$ então, a escolha pelo decassílabo carrega em si alguns significados, como a expressão dinâmica, fluente e contínua do texto teatral. Afirma Oliva Neto que a tradução de Bocage de Metamorfoses, de Ovídio, em decassílabos, reduz o número de sílabas dos hexâmetros ovidianos e, consequentemente, aumenta o número de versos na versão portuguesa:

Bocage [...] empregara o decassílabo e, ainda não preocupado com o fato de desprender um número maior de versos, não procura, condensando, reduzir ou resumi-los. Como a unidade rítmica do poema é um verso mais conciso do que o dodecassílabo e o alexandrino - a tradução no todo, a despeito da maior dimensão que assume, ritmicamente é de uma concisão dinâmica. ${ }^{22}$

Além dessa equivalência métrica, buscar-se-á, neste projeto de tradução, a identificação dos recursos expressivos poéticos, criadores de conotação, diretamente no texto de partida. Tais recursos serão relacionados à construção de um idioma estilístico senequiano e, em seguida, observarse-á como a conotação, ou seja, uma linguagem em que predomine a função poética (Jakobson, 2005, p.128), polissêmica por natureza, atua para a conquista de cada efeito expressivo, ou seja, como ela é utilizada como veículo de expressão. Assim, esse tipo de tradução consiste em uma transposição criativa dos efeitos de sentido do texto de partida.

\footnotetext{
${ }^{19}$ Cf. Dezotti, 1990, p. 127.

${ }^{20}$ Cf. Vieira, 2007, p. 139.

${ }^{21}$ Cf. Paz, 1972, p. 61.

${ }^{22}$ Cf. Oliva Neto, 2007, p. 26.
} 


\section{Outras premissas e tendências do projeto tradutório}

Já foram apresentadas neste artigo a concepção de tradução e algumas das escolhas tradutórias relacionadas à expressividade como um todo e à metrificação, mais especificamente. Agora, tratar-se-á de outros aspectos envolvendo o presente projeto tradutório.

É frequente nas tragédias do corpus a presença de enjambements e de mudanças de personagens no meio dos versos. Assim, a tradução deverá procurar valorizar o uso desses recursos. Quanto aos idiomatismos, ou seja, aqueles modos de dizer próprios de um dado ambiente linguístico e cultural, como as metáforas fixas, que diferem radicalmente de uma língua para outra, eles serão analisados caso a caso. Há de se valorizar a cultura latina, com menção ao uso vocabular nas notas de rodapé; entretanto, a versão em língua portuguesa procurará ser fluente e, para isso, a busca de equivalências idiomáticas e culturais nesta língua está no horizonte deste projeto tradutório.

As escolhas lexicais como um todo deverão visar a uma fluência em português, ou seja, nem sempre os vocábulos da tradução serão aqueles que mais se aproximam filologicamente da palavra latina do texto de partida. Por exemplo, o verso 115 de Oedipus, ausus Eois equitare campis foi traduzido por Klein (2005) por "Que ousou cavalgar os campos eoos". A tradução de Eous, a, um ("do Oriente") por "eoos” tem, certamente, a intenção de trazer ao texto de chegada um vocábulo com radical próximo ao utilizado no texto de partida. Além disso, o tradutor em questão procurou manter a estranheza em relação a essa palavra - existente na própria língua latina, já que se trata de um empréstimo grego. Contudo, essa escolha lexical prejudica a clareza da versão, uma vez que o leitor não encontrará em dicionários de língua portuguesa o significado da palavra empregada pelo tradutor. Uma solução que, dentro do presente projeto, manteria algo dessa estranheza sem prejudicar a compreensão seria: "Que ousou orientais campos galgar".

Quanto às escolhas sintáticas, a fluência buscada diz respeito a uma preocupação com o fato de que a tradução que se faz é de textos teatrais, isto é, de falas de personagens trágicos, e, como tal, demanda certa naturalidade e fluidez, ainda que seja culta, solene e tensa. É claro que o texto latino possui inversões, assim como o português também pode ter — isso não atrapalha a fluência em língua latina (essa é uma característica própria desse idioma e aparece inclusive em textos não poéticos), mas é preciso cuidado para que a fluência em português também não seja prejudicada.

Também é importante que seja observada a recorrência de termos no texto de partida, para que a repetição proposital realizada pelo autor seja recriada na tradução. Além disso, a recorrência de termos também sugere 
a ligação da temática com a seleção lexical do autor e, por isso, há que investigar se o uso de determinado vocábulo está ligado a alguma menção às obras filosóficas senequianas, a determinado elemento de construção das personagens, entre outras possíveis relações a serem examinadas.

Serão preparadas notas de referência com a função de servir como subsídio para leitura. Elas são fundamentais por realizarem a ponte entre as culturas do texto e do leitor de hoje em dia, já que língua e cultura são indissociáveis, e os romanos estão histórica e temporalmente muito distantes de nós. As notas acrescentarão comentários sobre a cultura romana e sobre a língua latina pertinentes ao texto.

Essas premissas auxiliarão na busca pelo idioma estilístico senequiano no tratamento do mito de Édipo, sendo possível, a partir de todas as análises propostas, encontrar um paralelo dentro da língua materna (texto de chegada) para a transposição dessas duas obras de Sêneca ao português brasileiro.

\section{As qualidades de um rei}

Feita a devida explanação sobre o projeto tradutório, passa-se a exemplificar o que será feito com as tragédias em questão a partir da tradução expressiva de um pequeno trecho (de v. 654 a 659) da tragédia Fenícias, de Sêneca, a seguir apresentado e escandido:

\section{ETÉOCLES}

$\begin{array}{llllll}1 & 2 & 3 & 4 & 5 & 6\end{array}$

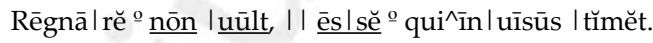

$\begin{array}{llllll}1 & 2 & 3 & 4 & 5 & 6\end{array}$

sĭmŭl îs $\mid$ tă ${ }^{o}$ mūn $\mid$ dīi $\mid$ | cōn $\mid$ dĭtōr | pŏsŭīt | děŭs,

$\begin{array}{lllllll}1 & 2 & 3 & 4 & 5 & 6\end{array}$

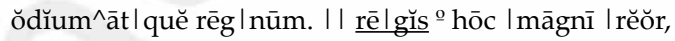

$\begin{array}{llllll}1 & 2 & 3 & 4 & 5 & 6\end{array}$

Ŏdĭa^īp | să ${ }^{o}$ prĕmĕ | rĕ. I | mūl| tă o dŏmĭ | nāntēm | uĕtăt

$\begin{array}{llllll}1 & 2 & 3 & 4 & 5 & 6\end{array}$

ămōr | sŭō | rūm; | | plūs | ̌̆n ${ }^{\circ} \overline{1} \mid$ rātōs | lĭcĕt.

$\begin{array}{llllll}1 & 2 & 3 & 4 & 5 & 6\end{array}$

quī uūlt |ămā | rī, | | lān | guĭdā I rēgnāt I mănū.

(Sen., Phoen., 654-9) 
O trecho está localizado no final do excerto restante da segunda parte da tragédia, em que os irmãos Etéocles e Polinices são impedidos de lutar pela intervenção de Jocasta, que tenta fazer com que os filhos se entendam e cessem as desavenças. Ela se coloca fisicamente entre os dois e argumenta a favor da paz. Os irmãos continuam a se desentender e a discussão é interrompida, não havendo final para a tragédia. Outrora, Etéocles e Polinices haviam celebrado um acordo pelo qual se comprometiam a alternar-se anualmente no trono, mas aquele não cumpriu com o combinado e este resolve invadir a cidade para tomar o trono para si.

No trecho, há referência a um tema filosófico amplamente tratado por Sêneca em sua obra filosófica: a ira. Em De ira, ${ }^{23}$ Sêneca afirma ser a ira o sentimento

[...] mais abominável e violento de todos. Nos outros há realmente algo de tranquilo e pacífico; este é totalmente veemente e está no ímpeto da dor, furioso com um desejo quase inumano de armas, de sangue, de suplícios, até que, indiferente a si mesmo, prejudique a um outro, precipitando-se sobre seus próprios dardos e ávido de uma vingança que arrasta consigo aquele que se vingou. ${ }^{24}$

Em Fenícias, Édipo se diz possuído exatamente por esse sentimento descrito pela obra filosófica senequiana, exatamente em acordo com o trecho acima citado: Tumet animus ira, feruet immensum dolor,/ maiusque quam quod casus et iunenum furor/ conatur aliquid cupio ("[Meu] espírito está inflado de ira, [minha] dor arde intensamente, e eu desejo algo maior do que (aquilo que) o destino e o furor desses jovens empreende[m]"). ${ }^{25}$

De acordo com o próprio autor, a ira consiste em uma loucura momentânea. ${ }^{26}$ Sêneca descreve as diversas faces da ira:

A diferença entre ela [a ira] e a irascibilidade é evidente; é como diferenciar um homem embriagado de um alcoólatra, ou um

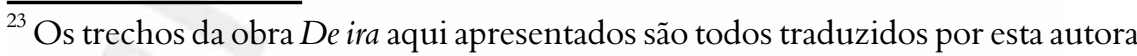
a partir do texto latino de Harvard University Press (Sêneca, 1928).

${ }^{24}$ Sêneca, Dial., III, 1, 1: [Exegisti a me, Nouate, ut scriberem quemadmodum posset ira leniri, nec immerito mihi uideris hunc praecipue affectum] pertimuisse maxime ex omnibus taetrum ac rabidum. Ceteris enim aliquid quieti placidique inest, hic totus concitatus et in impetus doloris est, armorum sanguinis suppliciorum minime humana furens cupiditate, dum alteri noceat sui neglegens, in ipsa irruens tela et ultionis secum ultorem tracturae auidus. ${ }^{25}$ Sêneca, Phoen., v. 352-354.

${ }^{26}$ Sêneca, Dial., III, 1, 1.
} 
homem tímido de um medroso. Um homem irado pode não ser um homem irascível; e um homem irascível, às vezes, pode não estar irado. Omitirei as outras [categorias] que, entre os gregos, distinguiam a ira em tipos com numerosos nomes, já que entre nós não há vocábulos próprios, ainda que digamos "colérico" e "hostil", não menos que "irritado", "raivoso", "vociferante", "intratável", "áspero", que são diferentes aspectos da ira; entre esses é possível considerar o impertinente, refinado tipo de irascibilidade. De fato, algumas iras se estabelecem no grito, outras são não menos persistentes que frequentes, umas são furiosas nas mãos e moderadas nas palavras, outras são excessivas no amargor das palavras e das injúrias; algumas não vão além de queixas e de aversões, outras são fortes e profundas e voltadas para dentro. Outras mil faces tem esse mal multiforme. ${ }^{27}$

Considerando as variadas faces da ira propostas por Sêneca, enumeram-se a seguir alguns termos usados pelo autor no texto de Fenícias, que se ligam a esse campo semântico: crudelis, cruente, dirus, execrabilis, ferox, feruidus, furens, furo, furor, incestificus, infandus, impius, inuisus, ira, iratus, monstrum, nefas, nefandus, odium, pestifer, saeuus, scelestus, scelus, semifer.

Além desses termos, há ainda que se considerar a existência dos contextos construídos pela forma de se contar o mito, que sugerem o sentimento do furor, do ódio, da ira. Nomes como esses são dados, em Fenícias, para atitudes atrozes como as de Édipo e de seus filhos Etéocles e Polinices. São ações impensadas, contra a razão humana. Em sua obra filosófica, Sêneca procura levar à reflexão sobre como acabar com a ira —é possível controlar essa loucura momentânea da mesma forma, por exemplo, com que um médico procura acabar com uma enfermidade. ${ }^{28}$

Em v. 654 a 659, há a utilização dos seguintes vocábulos: inuisus, odium, odia e iratos. Assim, é possível observar a relação existente entre as

\footnotetext{
${ }^{27}$ Sêneca, Dial., III, 1, 4: Quo distet ab iracundia apparet; quo ebrius ab ebrioso et timens a timido. Iratus potest non esse iracundus; iracundus potest aliquando iratus non esse. Cetera, quae pluribus apud Graecos nominibus in species iram distinguunt, quia apud nos uocabula sua non habent, praeteribo, etiam si amarum nos acerbumque dicimus, nec minus stomachosum, rabiosum, clamosum, difficilem, asperum, quae omnia irarum differentiae sunt; inter hos morosum ponas licet, delicatum iracundiae genus. Quaedam enim sunt irae, quae intra clamorem considant, quaedam non minus pertinaces quam frequentes, quaedam saeuae manu uerbis parciores, quaedam in uerborum maledictorumque amaritudinem effusae; quaedam ultra querellas et auersationes non exeunt, quaedam altae grauesque sunt et introuersus uersae. Mille aliae species sunt mali multiplicis.

${ }^{28}$ Sêneca, Dial., III, 1, 6.
} 
obras filosófica e trágica para teorizar e exemplificar, respectivamente, as consequências das paixões extremadas. Nesse sentido, tais personagens podem configurar os exempla mythologica, que Lohner, seguindo uma longa tradição de leitura, define como:

[...] apresentação de uma galeria de caracteres mitológicos tradicionais, retratados não como figuras realistas, porém extremadas, em cuja composição parecem ter sido deliberadamente desconsiderados os limites de verossimilhança com o objetivo de gerar estereótipos de comportamento, aptos a figurar como exemplos. $^{29}$

Nas palavras de Herrera, "os exempla mythologica se inserem nas tragédias senequianas para reforçar o seu conteúdo através de suas diferentes funções e, tudo isso, sem renunciar ao seu evidente valor estético". ${ }^{30}$

Assim, o trecho escolhido neste artigo para demonstrar o resultado pretendido com o presente projeto tradutório, dialoga com a intenção filosófica de tratar do tema da ira. As palavras destacadas pelas cesuras levam à ênfase dada pela personagem a non uult, mundi, regis, premere, multa, plus in. Esses termos auxiliam na construção de sentido da mensagem passada acerca das qualidades de um rei: 1) "NÃO QUER reinar quem teme ser odiado" (non uult reafirma a incompatibilidade existente entre reinar e temer o ódio); 2) "o deus criador DO MUNDO fez juntos o ódio e a realeza" (mundi demonstra que ódio e realeza estão juntos em todo o mundo, não importando a época que se analise); "é próprio de um grande REI COMPRIMIR estes ódios" (regis e premere delimitam a tarefa de qualquer rei: juntar realeza e ódio — sem essa união não há reino, segundo a argumentação proposta no trecho); "o amor dos seus impede quem domina de MUITAS COISAS" (multa denomina as inúmeras tarefas de um rei que são impossíveis de serem realizadas quando alguém quer e busca ser amado); "aos irados é permitido MAIS" (plus in traz a dimensão do poder que é possível alcançar quando se abdica do amor).

Além disso, a métrica dos versos em questão não separa por nenhum tipo de cesura os itens que, já no conteúdo, são inseparáveis: odium atque regnum. Estão juntos no conteúdo e também na expressão, inclusive unidos prosodicamente por uma sinalefa. Também estão da mesma maneira juntos os termos simul ista, fazendo referência aos mesmos itens mencionados.

\footnotetext{
${ }^{29}$ Cf. Lohner, 2009, p. 12.

${ }^{30}$ Cf. Herrera, 1997, p. 221 (trad. minha).
} 
As cesuras principais, no trecho, estão todas localizadas no meio do terceiro pé e dividem o verso ao meio, proporcionando, em quase todos os casos, versos simétricos. Quanto à métrica, os v. 654 e 655 apresentam cesura secundária no pé; já nos v. 656, 657 e 658 a cesura secundária ocorre no quarto pé. Quanto ao conteúdo, a simetria divide blocos de sentido: 1) "reinar não quer/ aquele que teme ser odiado"; 2) "juntamente estes do mundo/ o deus criador fez"; 3) "ódio e realeza./ creio ser próprio de um grande rei"; 4) "estes ódios comprimir./ impede quem domina de muitas coisas"; 5) "o amor dos seus;/ mais é permitido aos irados"; 6) "quem quer ser amado/ reina com mão fraca".

É interessante perceber a predominância de longas nos versos 654 e 659, justamente o primeiro e o último dessa fala de Etéocles. Esse uso pode ter como efeito de sentido tornar o tom do trecho ainda mais solene que o empregado nos demais versos. Além disso, os dois referidos versos trazem máximas importantes para a argumentação, que opõem "ser odiado" e "ser amado".

Além desses procedimentos métricos, também podem ser destacadas as figuras de linguagem presentes no trecho: 1) antítese (amor, no verso 658 se opõe a odium, no verso 656); 2) aliteração (repetição do som do "r" em regnare, regnum, regis, reor, suorum, iratos, amari, regnari); 3) quiasmo (construções cruzadas: a) regnare non uult, esse qui inuisus timet (verso 654) vs. qui uult amari $[. .$.$] regnat (verso 659$ ); b) regnare [...] inuisus (verso 654) vs. odium atque regnum (verso 656); c) regis (verso 656) vs. odia (verso 657); multa dominantem uetat (verso 657) vs. amor suorum (verso 658).

Segundo Lausberg, o quiasmo consiste no cruzamento de palavras, de funções sintáticas ou de proposições "relacionadas semanticamente entre si, dentro de um grupo frásico ou de um período" (1967, p. 235236). As inversões mencionadas - ao chamarem atenção aos paralelismos dos conceitos de "ódio" e "realeza" ou do seu inverso "amor" (ideia aqui correlata a pietas - "amor à pátria e à família") e "realeza"- servem à amplificação (amplificatio): se o conditor mundi dispôs esses termos em conjunção temporal (simul), o poeta os arranja em conjunção sintagmática.

Ao retomar insistentemente a construção em quiasmo, o texto senequiano aproxima essas ideias, caracterizando o conceito de "tirano" (tyrannus), que está relacionado com a conjunção de odium e regnum. ${ }^{32}$

\footnotetext{
${ }^{31}$ Por essa sugestão sobre o quiasmo e por todas as demais, agradeço ao parecerista anônimo de Nuntius Antiquus.

${ }^{32}$ Note-se essa aproximação dessa concepção de realeza com o fragmento do De ira citado por Martinho de Braga: Ira omnia ex optimo et iustissimo in contrarium mutat.
} 
Tal conjunção é imediatamente contraposta por dois quiasmos em 657659, presentes nas oposições entre dominantem-amor e amari-regnat, que amplificam por antítese a conjunção dessas ideias a partir da requintada disposição dos termos. Nesse último contraponto, Sêneca parece estar se remetendo ao ideal de bonus princeps presente em sua obra filosófica e que está muito longe da realidade de Etéocles. ${ }^{33}$

Por fim, levando-se em consideração todos os aspectos abordados, a proposta de tradução, em decassílabos, do trecho em questão, é a seguinte:

\section{Etéocles}

Reinar não quer quem teme ser malquisto.

Fez o deus criador do mundo juntos

ódio e reino: a um grandioso rei é próprio

os ódios reprimir, eis o que penso.

$\mathrm{O}$ amor dos seus impede a quem domina

muitas coisas; mais podem os irados.

Quem deseja amor reina com mão fraca.

\section{Considerações finais}

A tradução procurou manter as repetições vocabulares do texto de partida, bem como as oposições de conteúdo, as estruturas cruzadas e os demais efeitos de sentido observados. Além disso, buscou-se fluência na língua de chegada, fidedignamente à fluência formal que essa fala trágica teria em língua latina.

A tradução final das tragédias Édipo e Fenícias, na íntegra — o propósito da pesquisa de que este artigo faz parte — , pretende ser o resultado de um estudo mais completo sobre os procedimentos expressivos encontrados nos textos de partida, bem como sobre a recorrência desses procedimentos e seu grau de relevo perante os demais. Assim, um estudo minucioso dos versos será imprescindível para tal tarefa, como este artigo buscou mostrar.

Quemcumque obtinuerit, nullius eum meminisse officii sinit: da eam patri, inimicus est; da filio, parricida est; da matri, nouerca est; da ciui, hostis est; da regi, tyrannus est. — "A ira tudo muna de ótimo e justíssimo ao contrário. De quem quer que ela se apossa, não permite que ele lembre de nenhum dever; apresente-a ao pai, faz-se inimigo; ao filho, faz-se parricida; à mãe, faz-se madrasta; ao cidadão, faz-se um inimigo estrangeiro; ao rei, faz-se tirano" [Sêneca, Dial., III, 1, 3(fr1)1].

${ }^{33}$ Sêneca, Cl., XV, 3: Hoc ipso exemplo dabo, quem compares bono patri, bonum principem. "Exemplificarei assim: tu compararias esse bom príncipe ao bom pai". 
$\mathrm{Na}$ medida em que se estudarem os procedimentos poéticos, tais como o autor os utilizou (com que frequência, com que grau de importância, com que preferências de vocabulário e de estrutura sintática), estar-se-á, ao mesmo tempo, definindo o idioma estilístico senequiano no tratamento trágico do mito de Édipo.

\section{Referências}

ALMEIDA, G.; CAMPOS, H.; VIEIRA, T. Três tragédias gregas. São Paulo: Perspectiva, 1997.

BARBOSA, J. A. Envoi, a tradução como resgate. In: BARBOSA, J. A. As ilusões da modernidade. São Paulo: Perspectiva, 1986, p. 155-158.

BRODSKY, J. O filho da civilização. In: BRODSKY, J. Menos que um: ensaios. Trad. Sérgio Flaksman. São Paulo: Cia. das Letras, 1994, p. 73-87.

CAMPOS, H. O Prometeu dos barões. In: ALMEIDA, G.; CAMPOS, H.; VIEIRA, T. Três tragédias gregas. São Paulo: Perspectiva, 1997, p. 231-253.

CART, A. et alii. Gramática latina. Trad. M.-E. Soeiro. São Paulo: T.A. Queiroz/ Edusp, 1985.

de CASTILHO, J. F. (org.). Manuel Maria du Bocage: excerptos seguidos de uma notícia sobre sua vida e obras, um juízo crítico, apreciações de belezas e defeitos, estudos de língua. Tomo III. Rio de Janeiro/ Paris: Garnier/ A. Durand, 1867.

CHOCIAY, R. Em busca do estilo. Alfa, São Paulo, n. 27, p. 65-76, 1983.

DEZOTTI, J. D. O epigrama latino e sua expressão vernácula. Dissertação de mestrado inédita. São Paulo: FFLCH-USP, 1990.

EURIPIDES; SÊNECA; RACINE. Hipólito e Fedra: três tragédias. Estudo, tradução e notas de Joaquim Brasil Fontes. São Paulo: Iluminuras, 2007.

FILINTO ELÍSIO. Obras completas de Filinto Elísio. Ed. F. Morais Braga. Tomo IV — "Medea, de Sêneca". Braga: APPACDM, 1998-2004, p. 143-147.

HERRERA, G. R. Exempla mythologica en las tragedias de Séneca. In: RODRIGUES PANTOJA, M. (org.). Séneca dos mil años después: Actas del Congreso internacional conmemorativo del bimilenario de su nacimiento. Córdoba: Universidad de Córdoba y Cajasur, 1997, p. 211-221.

JAKOBSON, R. Linguística e comunicação. São Paulo: Cultrix, 2005.

KLEIN, G. R. O Édipo de Sêneca: tradução e estudo crítico. Dissertação de mestrado inédita. Campinas: IEL-UNICAMP, 2005.

LAUSBERG, H. Elementos de retórica literária. Lisboa: Calouste Gulbenkian, 1967. LOHNER, J. E. S. Posfácio: o "Agamêmnon" de Sêneca. In: SÊNECA. Agamêmnon. Trad., introdução, posfácio e notas J. E. S. Lohner. São Paulo: Globo, 2009, p. 111-155.

OLIVA NETO, J. A. Bocage e a tradução poética no século XVIII. In: OVÍDIO. Metamorfoses. Trad. M. M. B. du Bocage. São Paulo: Hedra, 2000, p. 9-33. 
PAZ, O. O Arco e a Lira. Trad. O. Savary. Rio de Janeiro: Nova Fronteira, 1982.

PEROZIM, J. O Édipo de Sêneca: do mito à razão. Tese de doutorado inédita. São Paulo: Universidade de São Paulo, 1977.

SÊNECA, L. A. Agamêmnon. Trad., introdução, posfácio e notas J. E. S. Lohner. São Paulo: Globo, 2009.

SENECA, L. A. Moral essays: vol. I. Trad. J. W. Basore. London: Harvard University Press, 1928.

SENECA. Tragedies: vol I. Edited with introduction and translation by John G. Fitch. London/ Cambridge, Mass.: Harvard University Press, 2002.

SENECA'S Tragedies: vol. II. Edited with introduction and translation by John G. Fitch. London/ Cambridge, Mass.: Harvard University Press, 2004.

SENECA. Seneca's Phoenissae. Introd. and commentary by M. Frank. New York: E. J. Brill, 1995.

SENECA. Hippolyto. Trad. Sebastião Francisco Mendo Trigozo. Lisboa: Academia Real das Sciencias, 1813.

SÊNECA. Trad. do trecho final de "Thyestes" por J. F. de Castilho. In: OVÍDIO. Os amores de P. Ovídio Nasão. Paráfrase por A. F. de Castilho, seguida pela Grinalda Ovidiana, por J. F. de Castilho. Rio de Janeiro: Bernardo Xavier Pinto de Sousa, 1858 (disponível em http://purl.pt/6255; acesso em 23/04/2009).

SÊNECA. Édipo, tragédia de Séneca. Trad. Cândido Lusitano - manuscrito da Biblioteca Pública de Évora (códice CXIII/ 1 - 1 d., fólios 65 a 108 vº).

VIEIRA, B. V. G. "Farsália", de Lucano, cantos I a IV: prefácio, tradução e notas. Tese de doutorado inédita. Araraquara: Universidade Estadual Paulista, 2007. 